JAN $1: 1992$ GA-A20672

\title{
THE DESIGN AND FABRICATION OF A TOROIDALLY CONTINUOUS CRYOCONDENSATION PUMP FOR THE DIII-D ADVANCED DIVERTOR
}

\author{
by \\ J.P. SMITH, C.B. BAXI, E. REIS, \\ M.J. SCHAFFER, K.M. SCHAUBEL, M.M. MENON
}

NOVEMBER 1991

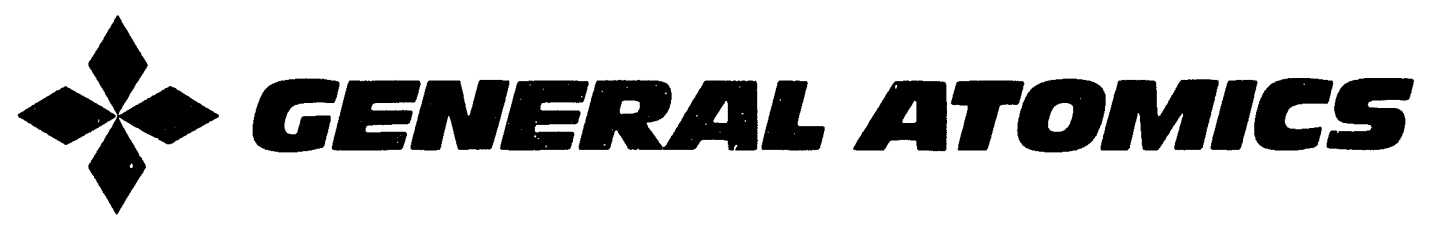

DISTRIBUTION OF THIS DOCUMENT IS UNLLANH: E: 


\section{DISCLAIMER}

This report was prepared as an account of work sponsored by an agency of the United States Government. Neither the United States Government nor any agency thereof, nor any of their employees, makes any warranty, express or implied, or assumes any legal liability or responsibility for the accuracy, completeness, or usefulness of any information, apparatus, product, or process disclosed, or represents that its use would not infringe privately owned rights. Reference herein to any specific commercial product, process, or service by trade name, trademark, manufacturer, or otherwise, does not necessarily constitute or imply its endorsement, recommendation, or favoring by the United States Government or any agency thereof. The views and opinions of authors expressed herein do not necessarily state or reflect those of the United States Government or any agency thereof. 


\title{
THE DESIGN AND FABRICATION OF A TOROIDALLY CONTINUOUS CRYOCONDENSATION PUMP FOR THE DIII-D ADVANCED DIVERTOR
}

\author{
by \\ J.P. SMITH, C.B. BAXI, E. REIS, \\ M.J. SCHAFFER, K.M. SCHAUBEL, M.M. MENON* \\ *Oak Ridge National Laboratory
}

This is a preprint of a paper to be presented at the 14th Symposium on Fusion Engineering, September 30-October 3, 1991, San Diego, California, and to be printed in the Proceedings.

Work supported by

Department of Energy

Contract DE-AC03-89ER51114

GENERAL ATOMICS PROJECT 3466

NOVEMBER 1991

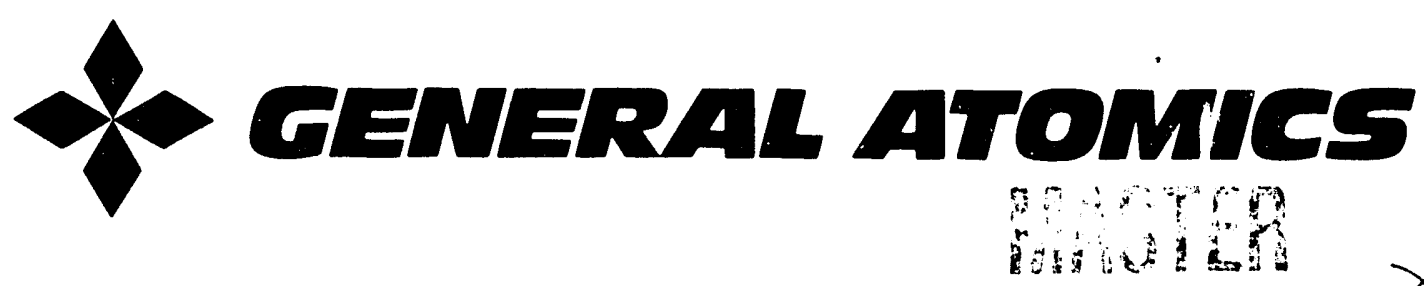




\title{
THE DESIGN AND FABRICATION OF A TOROIDALLY CONTINUOUS CRYOCONDENSATION PUMP FOR THE DIII-D ADVANCED DIVERTOR
}

\author{
J.P. Smith, C.B. Baxi, \\ E. Reis, M.J. Schaffer, K.M. Schaubel \\ General Atomics \\ P.O. Box 85608 \\ San Diego, California 92186-9784 \\ M.M. Menon \\ Oak Ridge National Laboratory \\ P.0. Box 2009 \\ Oak Ridge, Tennessee 37831
}

Abstract: A cryocondensation pump will be installed in the baffle chamber of the DIII-D tokamak in the spring of 1992. The design is complete and fabrication of this pump is in progress. The purpose of the pump is to study plasma density control by pumping the divertor. The pump is toroidally continuous, approximately $10 \mathrm{~m}$ long, in the lower outer corner of the vacuum vessel interior. It consists of a $1 \mathrm{~m}^{2}$ liquid helium cooled surface surrounded by a liquid nitrogen cooled shield to limit the heat load on the helium cooled surface. The stainless steel liquid nitrogen shell has a copper coating on it to enhance thermal conductivity, but the coating is broken to keep the toroidal electrical resistance bigh. The liquid nitrogen cooled surface is surrounded by a radiation/particle shield to prevent enerpictic particles from impacting and releasing condensed water rsolecules. The whole pump is supported off the water cooled vacuum vessel wall. Key design considerations were: how to accommodate the temperature differences between the various components, developing low heat leak paths for the various supports, and maintaining electrical insulation in a low pressure environment in the presence of induced voltage spikes. A single point ground for the system was used to limit disruption induced currents and the resulting electro-mechanical forces on the pump. A testing program was used to develop coating techniques to enhance heat transfer and emissivity of the various surfaces. Fabrication tests were done to determine the best method of attaching the liquid nitrogen flow tubes to their shield surfaces. A prototype sector of the pump was built to verify fabrication and assembly techniques.

\section{Introduction}

The second phase of the Advanced Divertor for the General Atomics DIII-D tokamak, a toroidally continuous cryocondensation pump, is presently being built and will be installed in the spring of 1992. The first phase of the DIII-D Advanced Divertor consisting of a biasable ring electrode and a toroidal gas baffle, was installed in August of 1990 . The cryopump will be installed under the toroidal gas baffle. The pump will enable experiments to study plasma exhaust and density control by divertor pumping, and it is expected to provide low density plasma for if current drive.

The pump was designed for a pumping speed of $50,000 \mathrm{l} / \mathrm{s}$, to have a removal rate of 20 torr/l-sec at an inlet pressure of 1 mtorr i1l. This removal rate is approximately equal to the fueling rate of $15 \mathrm{MW}$ of neutral beams. Recent experiments have shown the pressure under the baffle to be as high as $20 \mathrm{mtorr}$, so the removal rate of the pump will be much larger.

\section{Design}

A cross section of the pump and its location in the pumping plenum is shown in Fig. 1. The pump is comprised of a series of concentric stainiess steel tubes cut and assembled together. The pumping surface consists of a $10 \mathrm{~m}$ long, $25 \mathrm{~mm}$ diameter stainless steel tube with liquid helium flowing inside. It provides approximately $1 \mathrm{~m}^{2}$ of pumping surface. Surrounding the pumping surface are liquid nitrogen cooled shields which limit the steady state heat load on the helium system to less than 4 W. Surrounding the nitrogen cooled surfaces is a radiation/ particle shield to prevent energetic divertor particles from releasing water previously condensed on liquid nitrogen surfaces. The aperture to the pump is created by cutting windows in the radiation/particle and outer nitrogen shields. The inner nitrogen shieid provides shielding to the helium tube from incoming energetic particles. All particles entering the pump must bounce off a nitrogen cooled surface at least twice before hitting the helium surface. The nitrogen cooled suriaces are coated with an emissivity enhancing coating to absorb most of the incoming photons.

The liquid nitrogen components are designed to cool down in less than $30 \mathrm{~min}$ from $300^{\circ} \mathrm{K}$, and the helium surface will chill down from $300^{\circ} \mathrm{K}$ to $4^{\circ} \mathrm{K}$ in 4.5 min once the nitrogen shields are cooled. The use of helium glow discharge conditioning between shots in DIII-D requires rapid cooldown of the helium surface. During conditioning, helium pressures up to 2 mtorr are present for about $300 \mathrm{~s}$. The resulting large heat load on the liquid helium would drive the flow unstable. Thus, the pump will be shut off after every shot and then recooled after glow conditioning.

The flow pattern for the cryogens is shown in Fig. 2. There is a single feedthrough for the liquids which circulate around

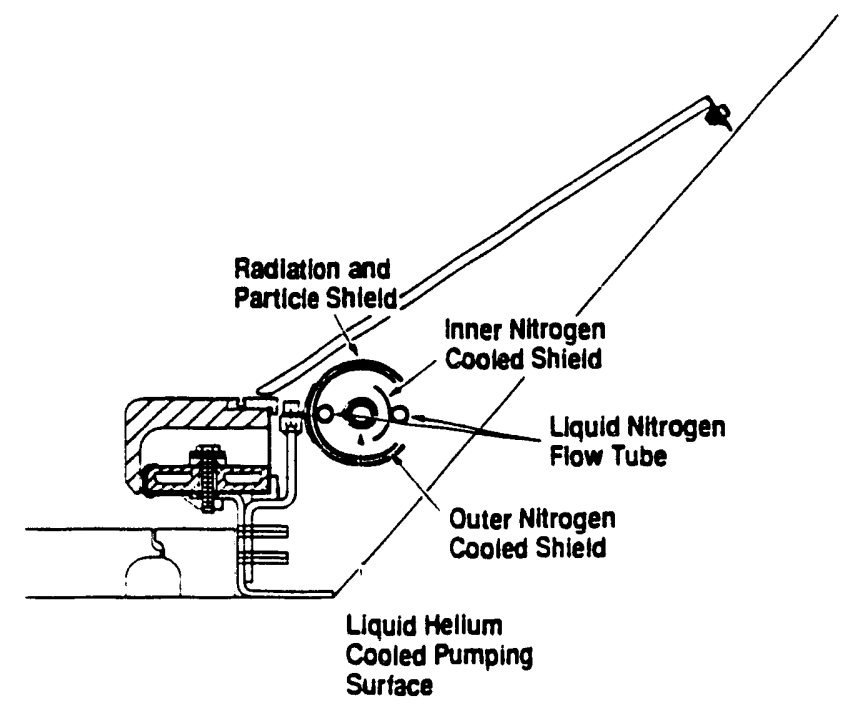

Fig. 1. Cross section of cryopump in DIII-D. 


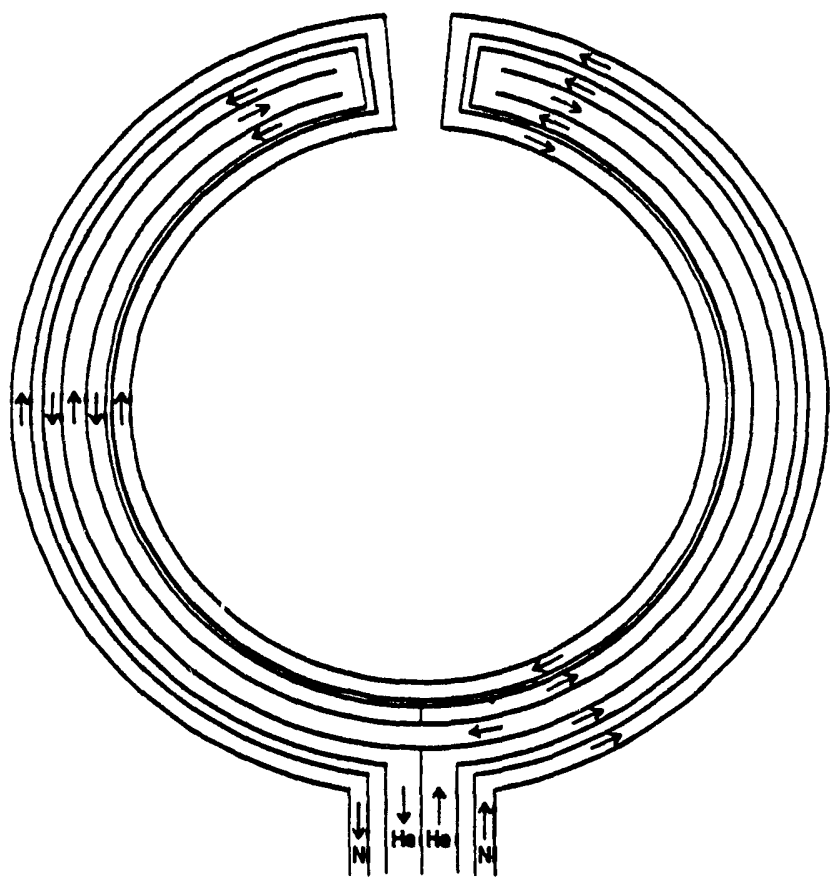

Fig. 2. Flow pattern for cryogens in the cryopump, as seen from above the machine projected onto the toroidal plane.

the vacuum chamber of DIII-D in a manner to eliminate full electrically conductive loops around the vessel. The full loops would give rise to large inductively driven currents resulting in extremely large electromagnetic loads. The helium flows in concentric tubes to keep a compact design and prevent a full toroidal loop. The liquid enters at the center of the pump, flows $180^{\circ}$ through the outer annular space, returns to the other end of the pump via the inner tube, and then returns to the feedthrough in the outer annular space. The heat exchanger effect during cooldown was both analyzed and tested [2]. The flow regime of the liquid helium is in the forced flow regime and enters the pump as saturated liquid and exits as lower pressure, lower temperature two-phase helium. The mass flow rate is designed to be $4 \mathrm{gm} / \mathrm{s}$ at $116 \mathrm{kPa}$. By minimizing the amount of gaseous helium and maintaining bubble flow, flow instability is eliminated as a concern. The flow stability has been tested at several heat loads i3!.

The single-feed location is also the system's single-point ground. The benefit of a single-point ground is the reduction of circulating currents that could either provide resistive heating or increase the electromagnetic loads on the pump. The helium and nitrogen shells are electrically insulated from one another and from the particle/radiation shell. The particle/radiation shell is made in $30^{\circ}$ sections supported at one location per section back to the vacuum vessel wall and is at local vessel electrical potential. The helium and nitrogen shields are fabricated in $90^{\circ}$ sections and welded together during installation inside the vacuum vessel.

The supports for the cryopump are designed to have !le pump change in circumference rather than in radius when cooled from $300^{\circ} \mathrm{K}$, because there was not space enough for this movement and still provide support for the electromagnetic loads. The support system relies on toroidal sliding between alumina ceramic pieces and stainless steel.

The liquid helium tubes are supported off the inner nitrogen sheli by a pair of conicaily wound compression spnngs every $45^{\circ}$ (Fig. 3). The springs provide a long heat leak patb with all supports summing to a heat load of only $0.1 \mathrm{~W}$ to the helium. Electrical insulation between the helium and nitrogen systems is provided by two alumina rings per support. The alumina rings are designed to allow the helium tube to slide with respect to the nitrogen shield, thus taking up the differential thermal expansion in changing the circumference of the pump. However, if one support jams and the helium tube does not slide through the support, the springs have enough axial travel to ailow the pump to change in circumference. The lateral stiffness of the spring is designed to limit the "Bourdon tube" movement of the belium tube due to the internal pressure. The internal pressure is limited by relief valves on the helium system to $172 \mathrm{kPa}$. Also, the lateral stifiness reacts the electromagnetic and gravitational loads on the helium tubes.

The liquid nitrogen shield is supported from the radiation/ particle shield by alumins buttons. The buttons are located in sets of three, and there are at least three sets per $30^{\circ}$ section of the radiation/particle shield. The buttons allow for sliding between the nitrogen shell and the radiation/particle shield and the differential growth is again taken up by a circumferential change in length. The radial stiffecss of the supports of the radiation/particie shield to the vessel wall is large enough to guarantee the movement in the circumferential direction.

\section{Manufacture and Assembly}

Different methods of manufacturing the pump were studied to limit the distortion of the components and give stress-free parts. Stock stainiess stcel 304 L tubes were taken and rolled to the appropriate radius. The rolled sections were annealed in a vacuum furnace for stress relief Laser cutting was chosen over either torch cutting or traditional machining to form the windows in the side of the tube for the pumping aperture.

The liquid nitrogen flow tubes are attached to their shells by a series of $25 \mathrm{~mm}$ long plug welds spaced every $50 \mathrm{~mm}$. Both nitrogen shells were originally rolled to a larger radius than nominal to allow for shrintage during welding. The inside of the outer nitrogen shell is plasma sprayed with a $13 \%$ titanium dioxide- $87 \%$ aluminum oxide coating to enhance emissivity and to reduce the heat load on the helium tube. The measured coating emissivity is greater than 0.75 at $10.6 \mu \mathrm{m}$ wavelength. The outer surface of the inner nitrogen shell also has the coating.

The outer nitrogen shell has copper stripes flame sprayed on the outside to enhance aximuthal thermal conductance. This is needed to keep a maximum temperature of $110^{\circ} \mathrm{K}$. The stripes are $25 \mathrm{~mm}$ wide, spaced every $50 \mathrm{~mm}$ along the length of the pump. The copper is not toroidally continuous in order to keep the electrical resistance high and minimize the electromagnetic forces on the pump. The stripes coincide with the plug welds to maximize the thermal conductance.

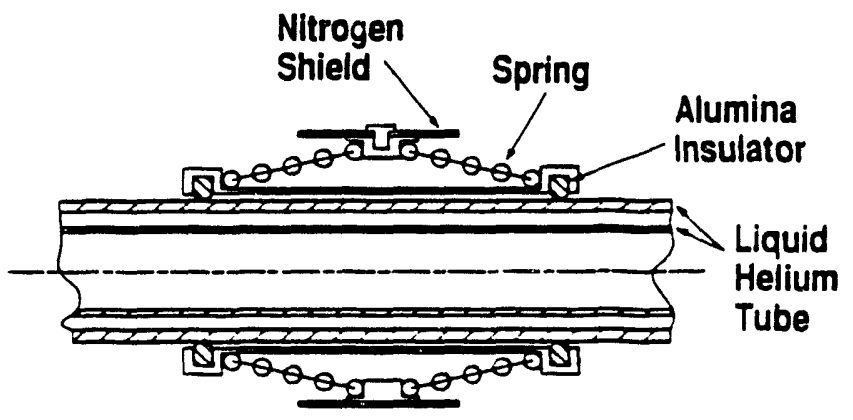

ig. 3. Low heat leak liquid helium support. 
At the four locations for the electric and water feeds of the ring electrode, the cross section of the pump is modified (Fig. 4) to give room for the electrical insulation of these feeds. This also reduces the pump aperture by half for about $20 \%$ of the pump toroidal circumference.

The pump is built up on a tooling plate in $90^{\circ}$ sectors. The belium line is installed inside the inner nitrogen shell and

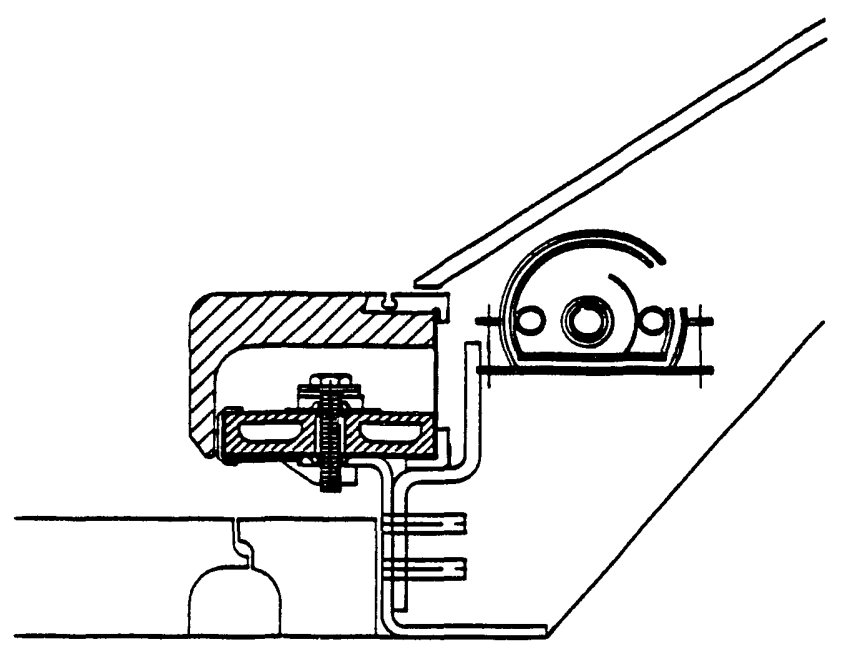

Fig. 4. Modified crose section of the cryopump in regions of the biased ring electrode's water and power feeds. then the inner nitrogen shell is weided inside the outer nitrogen shell. The feedthrough is trial fit into place and all welds are checked for accessibility. The four nitrogen sheil assemblies are then brought into the vessel and welded together. The radiation' particle shields are slid over the nitrogen shield into place and installed.

A prototype $90^{\circ}$ sector of the pump was built to verify the manufacturing processes and assembly sequence prior to the production of the final pump.

\section{Acknowiedgment}

This work wes sponsored by the U.S. Department of Energy under Contract No. DE-AC03-89ER51114.

\section{References}

(1] Menon, M.M., etal., "Particle Exhaust Scheme Using an In-Vessel Cryocondensation Pump," GA Report to be published.

[2] Baxi, C.B., etah, "Thermal Design, Analysis and Experimental Verification for a DIII-D Cryogenic Pump," in Proc. Second Int. Symp. on Fusion Nuclear Technology, June 2-7, 1991, Karisrube, FRG.

[3] Schaubed, K.M., etah, "Design of the Advanced Divertor Pump Cryogenic System for DIII-D," to be presented at the 14th Fusion Engineering Conf., September 30October 3, 1991, San Diego, California. 
Q 